\title{
The Royal Australasian College of Physicians position statement on refugee and asylum seeker health
}

\section{"The RACP \\ does not \\ condone held \\ detention in \\ any form and \\ considers held \\ detention to \\ be a significant \\ breach of \\ human rights"}

Georgia A Paxton MB BS(Hons), MPH, FRACP

Sarah Cherian MB BS(Hons), FRACP, PhD 2.3

Karen J Zwi MB BCh, FRACP, MRCP(UK) $)^{4.5}$

on behalf of the RACP Working Party for Refugee Working Party for Refugee
and Asylum Seeker Health

I Royal Children's Hospital, Melbourne, VIC.

2 Princess Margaret Hospital for Children, Perth, WA.

3 University of Western Australia, Perth, WA.

4 University of New South Wales, Sydney, NSW.

5 Sydney Children's Hospitals Network, Sydney, NSW.

georgia.paxton@ rch.org.au

doi: 10.5694/mjal5.00593
$\mathrm{R}$ efugee and asylum seeker health is important in the setting of increasing global forced migration, and the particular physical and mental health issues faced by these groups. The Royal Australasian College of Physicians (RACP) has identified refugee and asylum seeker health as a policy priority, recognising large refugee-background populations in Australia and New Zealand, increased asylum seeker boat arrivals to Australia during 2009-2013, the duration and impact of Australian immigration detention, and complex and changing Australian asylum policy. Key demographics of refugees and asylum seekers are shown in Box 1.

The previous RACP policy (2007) focused on refugee children, whereas the 2015 position statement extends the RACP position across the lifespan and includes both refugees and asylum seekers. The position statement has been developed with extensive consultation across health disciplines (Box 2), with the intention of changing the discourse on refugees and asylum seekers, providing an evidence-based summary of relevant health issues, and highlighting the health impact of refugee and asylum policy. The position statement and accompanying policy summary of evidence are available at https://members. racp.edu.au/page/asylum-seekers.

\section{Main recommendations}

The position statement considers four key areas: health assessments, access to health care, promoting long-term health in the community, and asylum seekers in held detention. Each section summarises issues of concern, outlines the actions of the RACP, and provides recommendations for different levels of government and local service providers.

\section{Health assessments}

This section addresses post-arrival screening, transfer of health screening information, and age assessments for refugee and asylum seeker children and young people. The RACP suggests that all refugees and asylum seekers should be offered a voluntary comprehensive assessment of their physical and mental health on arrival. The RACP reiterates serious concern over the lack of transparency in Australian immigration detention health screening and the risks associated with rapid health screening processes used before transfer to offshore detention. The RACP proposes that unaccompanied children and young people undergoing age assessment should have an independent advocate present during the assessment.
1 Key demographics of refugees and asylum seekers

Global context (2013)

- 51.2 million forcibly displaced people

- 16.7 million refugees, $86 \%$ hosted in nearby or developing countries

- More than 1 million asylum applications - 100000 in Germany, 50 000-80 000 in each of the United States, South Africa, France, Sweden and Malaysia

Australia

- Over 800000 refugee arrivals since 1945

- 13750 Humanitarian Programme visas annually, due to increase to 18750 by 2018-19

- 51637 asylum seeker boat arrivals during 2009-2013

- As of March 2015, there were:

- 27216 asylum seekers on bridging visas in the community

- 2512 asylum seekers in community detention

- 1848 asylum seekers in held (locked) detention on Christmas Island and the mainland

- 1707 asylum seekers in held (locked) detention on Nauru or Manus Island

New Zealand

- Over 40000 refugee arrivals since 1976

- 750 "quota refugees" annually, including up to 300 places for family reunion

- 300 Refugee Family Support Category entrants annually

- About 300 asylum seekers arriving by plane annually; no asylum seeker boat arrivals

\section{Access to health care}

Refugees and asylum seekers face considerable barriers to accessing health, mental health, immunisation, dental and maternity services after arrival, compounded by varied entitlements and supports. For asylum seekers in Australia, a lack of, or lapse in, Medicare eligibility affects their health service access and is likely to increase overall costs to the health, immigration and service systems. The RACP supports equitable access to health care for refugees and asylum seekers, using targeted strategies and casework support and emphasising the importance of language service support for all health care episodes.

\section{Promoting long-term health in the community}

The RACP acknowledges the economic, social and civic contribution of refugee-background communities. Available evidence suggests they do not represent a greater cost to, or burden on, health systems over the long term. The RACP endorses early support for new arrivals, with flexible casework and settlement services that are needs-based and not restricted by age, visa status 
2 External consultations in developing the position statement

The Royal Australasian College of Physicians (RACP) is grateful to the following organisations for their review and suggestions, and regards this support for the RACP position as a significant achievement.

- Andrew \& Renata Kaldor Centre for International Refugee Law

- Australian Association of Social Workers

- Australasian Society for Infectious Diseases

- Australian Medical Students' Association

- Australian Psychological Society

- College of Nurses Aotearoa (NZ)

- Forum of Australian Services for Survivors of Torture and Trauma

- Melbourne Children's Campus

- New Zealand College of Midwives

- New Zealand College of Public Health Medicine

- New Zealand Medical Association

- Public Health Association of Australia

- Royal Australian and New Zealand College of Psychiatrists

- Royal Australian College of General Practitioners

- Royal New Zealand College of General Practitioners

- Sydney Children's Hospital Network

- Women's Healthcare Australasia

or time or mode of arrival. The RACP argues for equitable access to education, English language support, and opportunities to work and train for meaningful employment, to promote long-term health. Restricting work rights for asylum seekers (as occurred for most asylum seekers in Australia throughout 2012 to early 2015) is contrary to maintaining health and is likely to increase overall costs due to extreme social disadvantage.

Assessment of asylum seeker claims for refugee status was suspended in late 2012, creating profound uncertainty, with consequent impact on health. There is an urgent need to recommence processing asylum seekers' refugee claims, to allow people to move forward with their lives. The RACP supports pathways to permanent protection and does not support the use of temporary protection visas (TPVs), based on evidence that TPVs are associated with worse physical and mental health outcomes.

\section{Asylum seekers in held detention}

Australia uses mandatory immigration detention for asylum seekers arriving by boat, and indefinite immigration detention is possible under Australian law. New Zealand legislation also allows for mandatory detention of asylum seekers if they are part of a "mass arrival" by boat. However, New Zealand has not had asylum seeker boat arrivals and, in practice, immigration detention is an open arrangement at the Mangere Refugee Resettlement Centre.

Australian held (locked) detention is harmful to the physical and mental health of people of all ages in the short and long term. These findings are consistent across available research, parliamentary inquiries and the 2014 Australian Human Rights Commission (AHRC) report on detained children. In addition to the human costs, the financial costs of detention are enormous, estimated at \$3.3 billion over the 2013-14 financial year.

Immigration detention facilities are prison-like, institutional and monotonous environments. The combination of the environment, uncertainty, lack of meaningful activity, erosion of family life and interrupted schooling contributes to high rates of mental health problems, self-harm and attempted suicide in children and adults. Since September 2014, the average duration of detention has been around 400 days; many people have been detained for over 18 months. The risks of held detention are amplified in offshore detention facilities because of infrastructure challenges, limited access to specialist health services, ongoing risk of destabilisation and uncertainty around the future and settlement options.

Held detention presents an extreme and unacceptable risk to children's development and mental health, especially for unaccompanied children. Children in held detention cannot be protected from physical violence and mental distress in the adults around them, and are likely to be at risk of physical abuse, sexual abuse, maltreatment and neglect. Significant concerns were raised by the AHRC report and the Moss Inquiry into child protection issues on Nauru. Despite these risks, there is no clear or consistent child protection framework in Australian immigration detention.

The RACP does not condone held detention in any form and considers held detention to be a significant breach of human rights. The RACP expresses extreme concern over the use of offshore detention and does not support asylum seekers being transferred to, detained in or resettled in regional processing countries. The RACP also expresses extreme concern that unaccompanied children in detention are under the guardianship of the Minister for Immigration and Border Protection, who is paradoxically responsible for both acting in the children's best interests and for placing them in held detention.

The RACP acknowledges the ethical issues of providing health care in detention and the tension in defining a standard of care. Health care providers cannot address health problems caused by held detention while people are still detained. The RACP calls for an independent cross-disciplinary health advisory body to oversee health service provision for asylum seekers.

The RACP supports all doctors and health professionals in their duty of care to their patients, including the need to maintain professional standards and to speak out in support of ethical care. The RACP will continue to advocate for best practice and urges a rights-based and humane approach to people seeking asylum.

Acknowledgements: We acknowledge the other members of the RACP Working Party for Refugee and Asylum Seeker Health: Joshua Francis, Mitchell Smith, Lesley Voss, Vanessa Johnston, Andrew Block, Kate Napthali and Emily Ofner. Karen Zwi is Chair of the Working Party.

Competing interests: No relevant disclosures.

Provenance: Not commissioned; not externally peer reviewed.

(c) 2015 AMPCo Pty Ltd. Produced with Elsevier B.V. All rights reserved. 